\title{
Piperlongumine Blocks JAK2-STAT3 to Inhibit Collagen-Induced Platelet Reactivity Independent of Reactive Oxygen Species ${ }^{\dagger}$
}

\author{
Hengjie Yuan ${ }^{1,2}$, Katie L. Houck ${ }^{1}$, Ye Tian ${ }^{1,2}$, Uddalak Bharadwaj ${ }^{3}$, Ken Hull ${ }^{4}$, Zhou Zhou ${ }^{1}$, \\ Mingzhao Zhou ${ }^{4}$, Xiaoping $\mathrm{Wu}^{1}$, David J. Tweardy ${ }^{3}$, Daniel Romo ${ }^{4}$, Xiaoyun Fu ${ }^{1,6}$, \\ Yanjun Zhang ${ }^{5}$, Jianning Zhang ${ }^{2 *}$, Jing-fei Dong ${ }^{1,6 *}$ \\ 1 Bloodworks Northwest Research Institute, Seattle, Washington, United States of America, 2 Tianjin \\ Neurological Institute, General Hospital, Tianjin Medical University, Tianjin, China, 3 Division of Infectious \\ Disease, Department of Medicine, Baylor College of Medicine, Houston, Texas, United States of America, \\ 4 The Natural Products LINCHPIN Laboratory and Department of Chemistry, Texas A \& M University, \\ College Station, Texas, United States of America, 5 Medicine Division, Imperial College London, London, \\ United Kingdom, 6 Division of Hematology, Department of Medicine, University of Washington, School of \\ Medicine, Seattle, Washington, United States of America
}

* jfdong @BloodworksNW.org (JFD); jianningzhang @ hotmail.com (JZ)

\section{G OPEn ACCESS}

Citation: Yuan H, Houck KL, Tian Y, Bharadwaj U, Hull K, Zhou Z, et al. (2015) Piperlongumine Blocks JAK2-STAT3 to Inhibit Collagen-Induced Platelet Reactivity Independent of Reactive Oxygen Species ${ }^{\dagger}$. PLOS ONE 10(12): e0143964. doi:10.1371/journal. pone. 0143964

Editor: Zhenyu Li, University of Kentucky, UNITED STATES

Received: August 6, 2015

Accepted: November 11, 2015

Published: December 8, 2015

Copyright: @ 2015 Yuan et al. This is an open access article distributed under the terms of the Creative Commons Attribution License, which permits unrestricted use, distribution, and reproduction in any medium, provided the original author and source are credited.

Data Availability Statement: All relevant data are within the paper and its Supporting Information files.

Funding: This work is supported by 1) grants HL71895 and HL085769 from the National Heart, Lung, and Blood Institute and CA149783 from the National Cancer Institute; 2) the Cancer Prevention and Research Institute of Texas (RP100421); 3) the Tianjin Science and Technology Support Program of China (No.14ZCZDSY00020); 4) the Natural Science Foundation of China (No.13JCYBJC21900 and 12JCYBJC31500); 5) the John S. Dunn Gulf Coast Consortium for Chemical Genomics Discovery

\section{Abstract}

\section{Background}

Piperlongumine (PL) is a compound isolated from the piper longum plant. It possesses anticancer activities through blocking the transcription factor STAT3 and by inducing reactive oxygen species (ROS) in cancer, but not normal cells. It also inhibits platelet aggregation induced by collagen, but the underlying mechanism is not known.

\section{Objective}

We conducted in vitro experiments to test the hypothesis that PL regulates a non-transcriptional activity of STAT3 to specifically reduce the reactivity of human platelets to collagen.

\section{Results}

PL dose-dependently blocked collagen-induced platelet aggregation, calcium influx, CD62p expression and thrombus formation on collagen with a maximal inhibition at $100 \mu \mathrm{M}$. It reduced platelet microvesiculation induced by collagen. PL blocked the activation of JAK2 and STAT3 in collagen-stimulated platelets. This inhibitory effect was significantly reduced in platelets pretreated with a STAT3 inhibitor. Although $\mathrm{PL}$ induced ROS production in platelets; quenching ROS using excessive reducing agents: $20 \mu \mathrm{M}$ GSH and $0.5 \mathrm{mM}$ L-Cysteine, did not block the inhibitory effects. The NADPH oxidase inhibitor Apocynin also had no effect.

\section{Conclusions}

PL inhibited collagen-induced platelet reactivity by targeting the JAK2-STAT3 pathway. We also provide experimental evidence that PL and collagen induce different oxidants that 
Project; and 6) Tianjin Natural Science Foundation of China (No.13JCYBJC21900) and Tianjin Municipal Science and Technology Project (No.14ZCZDSY00020).

Competing Interests: The authors have declared that no competing interests exist. have differential effects on platelets. Studying these differential effects may uncover new mechanisms of regulating platelet functions by oxidants in redox signals.

\section{Introduction}

The long pepper (Piper longum) is a member of the Piper genus known to possess anti-allergenic, anti-inflammatory, and liver protecting properties $[1 ; 2]$. The fruit of $P$. longum has more than 600 known active compounds; among them is piperlongumine (PL, 5,6-dihydro-1-

[1-oxo-3-(3,4,5-trimethoxyphenyl]-2(1H) pyridinone). PL, related compounds, and chemically synthesized analogs are reported to have anti-cancer [2;3], gastric protective [4], anti-microbial [5;6], adipogeneic [7;8], and anti-atherosclerotic activities [9]. PL executes these diverse activities, in part, by targeting protein synthesis at the transcriptional and post-transcriptional levels [3;10-12]. Raj L, et al [11] reported that PL selectively induces the death of cancer or transformed cells, while preserving the viability of normal cells in vitro and in vivo. This targeted activity relies on PL's ability to increase intracellular reactive oxygen species (ROS), especially hydrogen peroxide and nitric oxide [11]. PL does so by binding and down-regulating activities of the enzymes glutathione S-transferase pi 1 (GSTP1) and carbonyl reductase 1 (CBR1)[11], resulting in a redox potential that is significantly tilted towards oxidation[3;11].

Paradoxically, PL was also reported to inhibit platelet activation, secretion, and aggregation induced by collagen, arachidonic acid, thromboxane, and platelet activating factor [13-15]. However, the known mechanisms involved in the inhibition of cancer cells do not support PL's actions in platelets. First, blocking gene transcription is unlikely to play a significant role in the anti-platelet activity of PL because platelets are anucleated cells with a limited capacity for protein synthesis. Furthermore, the inhibitory effect was detected within minutes after PL treatment, insufficient for significant transcription and/or translation activities to occur. Second, ROS is known to activate platelets and promote thrombosis [16;17]. Cross-linking GP VI by collagen stimulates platelets to produce ROS [18]. These conflicting data lead to a critical question of whether PL induces these diverse phenotypic changes in platelets and cancer cells by targeting different molecules or by acting on a single molecule that is active both transcriptionally and non-transcriptionally. A target of PL specifically for collagen-induced platelet activation and aggregation that emerged from our recent study is the transcription factor STAT3 [19].

STAT3 is a member of a family of seven closely related proteins and serves as a key signaling protein in the IL-6-induced acute phase reaction pathway [20]. In nucleated cells, IL-6 binds to the IL-6R $\alpha$-gp130 receptor complex, oligomerizing receptors to activate receptor-associated tyrosine kinases. These activated kinases phosphorylate tyrosine residues to create a docking site for STAT3 via its Src-homology 2 (SH2) domain [21], leading to the phosphorylation of STAT3 at residue Y705 and the formation of a tail-to-tail homo-dimer that accumulates in the nucleus to regulate the transcription of targeted genes. We have recently uncovered a non-transcriptional role of STAT3 in a cross-talk between inflammatory IL-6-STAT3 and hemostatic/ thrombotic collagen-GP VI signals that renders platelets hyper-reactive in conditions of inflammation through a trans-signaling mechanism [22].

These published reports have led us to hypothesize that PL regulates a non-transcriptional activity of STAT3 to reduce platelet reactivity to collagen. Here, we present data from in vitro experiments on human platelets using PL and synthesized derivatives to support this hypothesis. This study was not designed to study the pharmacokinetics of PL, but to identify PL's 
molecular target(s) in regulating collagen-induced platelet activity and to explore roles of oxidative stress in platelet reactivity.

\section{Materials and Methods}

\section{Reagents}

Commercial reagents used in the study included: PL (Cayman Chemical Co., Ann Arbor, MI), the STAT3 inhibitor STA21 (Sigma Aldrich, St. Louis, MO), the JAK2-inhbitor AG490 (InvivoGen, San Diego, CA), the Syk inhibitor SykII (Merck Millipore, Billerica, MA), human recombinant IL-6 (R \& D Systems, Minneapolis, MN), the extracellular domain of human IL-6 receptor- $\alpha$ (R \& D Systems), Actinomycin (Sigma Aldrich), apocynin (Abcam Biochemicals. Cambridge, MA), free glutathione (GSH, Sigma Aldrich), L-cysteine (Sigma Aldrich), N-ethylmaleimide (NEM, Sigma Aldrich); dithiothreitol (DTT, Sigma Aldrich), fibrillary type I collagen (Helena laboratories, Beaumont, TX) and FITC-conjugated annexin V (BD Bioscience, San Jose, CA). Antibodies used in the study were: a FITC-conjugated monoclonal CD62p (BD Bioscience), a PE-conjugated monoclonal anti-CD42b (BD Bioscience), and antibodies for total and phosphorylated JAK2, STAT3, Syk, and PLC $\gamma \gamma 2$ (all from Cell Signaling Technologies, Danvers, MA).

\section{Methods}

Platelet aggregation. Whole blood was collected (anticoagulant: $3.2 \%$ sodium citrate) from healthy donors under protocol \#20121746 approved by the Western Institutional Review Board for Bloodworks Northwest via written informed consent. Platelet-rich plasma (PRP) was obtained by centrifugation of whole blood at $120 \mathrm{xg}$ for $20 \mathrm{~min}$ at $26^{\circ} \mathrm{C}$. Platelet counts in PRP were normalized to $3.0 \times 10^{5}$ platelets/ $\mu$ l with homologous plasma and treated with PL (12.5$100 \mu \mathrm{M})$, its synthetic analogs or other testing agents for $15 \mathrm{~min}$ at $37^{\circ} \mathrm{C}$. Platelet aggregation was induced in an optical aggregometer (Helena Laboratories) by fibrillar type I collagen or a collagen-related peptide (CRP) [22] and monitored for $5 \mathrm{~min}$ at $37^{\circ} \mathrm{C}$. Collagen was tested primarily at $5 \mu \mathrm{g} / \mathrm{ml}$ in order to test the inhibitory strength of PL activity, which is recommended by the manufacturer for clinical tests, but also tested at 2 and $10 \mu \mathrm{g} / \mathrm{ml}$ in a subset of experiments in order to detect the effects of PL on different concentrations of collagen. PL was also tested for platelet aggregation induced by $5 \mu \mathrm{M}$ of ADP or $50 \mu \mathrm{M}$ of thrombin receptor activating peptide (TRAP). To identify the target of PL, the following reagents were tested either alone or in combination with PL at doses indicated in the result section: STA21, AG490, SykII, Actinomycin-D, Apocynin, GSH and L-Cysteine.

Platelet activation. The effect of PL on collagen-induced platelet activation was measured by monitoring CD62p expression and calcium influx. CD62 expression was determined through the binding of a FITC-conjugated monoclonal antibody in PRP that was sequentially treated with PL and fibrillar type I collagen $(0.5-10 \mu \mathrm{g} / \mathrm{ml})$, each for $15 \mathrm{~min}$ at $37^{\circ} \mathrm{C}$. For collagen-induced platelet calcium mobilization, $20 \mu \mathrm{l}$ of PRP was mixed with $180 \mu \mathrm{l}$ of Tyrode's buffer $\left(138 \mathrm{mM} \mathrm{NaCl}, 2.9 \mathrm{mM} \mathrm{KCl}, 1.4 \mathrm{mM} \mathrm{MgCl}_{2}, 0.8 \mathrm{mM} \mathrm{CaCl}_{2}, 12 \mathrm{mM} \mathrm{NaHCO}_{3}, 5.5 \mathrm{mM}\right.$ glucose, $\mathrm{pH}$ 6.5) containing the Calcium Sensor Dye eFluor 514 ( $5 \mu \mathrm{M}$, final concentration, ebioscience, Inc., San Diego, CA). The mixture was immediately analyzed by flow cytometry [23]. Single platelets were gated on forward scatter and analyzed for fluorescence intensity over $60 \mathrm{sec}$ to obtain the basal level. They were then stimulated with collagen, and monitored for changes in fluorescence intensity for additional $5 \mathrm{~min}$ at room temperature.

Hopping Probe Ion Conductance Microscopy imaging. The effects of PL on the morphological changes and microvesiculation of platelets adherent to collagen were monitored using a modified ICnano Hopping Probe Ion Conductance Microscope (HPICM, Ionscope 
Ltd, UK) as previously described [24]. Briefly, PL-treated PRP was incubated on immobilized collagen $\left(10 \mu \mathrm{g} / \mathrm{ml}, 4^{\circ} \mathrm{C}\right.$ overnight) for $30 \mathrm{~min}$ at $37^{\circ} \mathrm{C}$. After washing, adherent platelets were scanned under an ICnano scan head with a nanopipette $(\mathrm{d}=60 \mathrm{~nm})$ connected to an external Axon MultiClamp 700B amplifier (Molecular Devices, USA). This amplifier monitored the ion-current flowing into the nanopipette tip and supplied a DC voltage of $+200 \mathrm{mV}$ between the nanopipette electrode and bath electrode. All experiments were carried out at $24-28^{\circ} \mathrm{C}$. Raw topography data were continuously acquired and linearly interpolated into images with ScanIC Image Viewer software version 1.0 (Ionscope Ltd, UK).

Measurement of platelet microparticles. Platelet microvesiculation induced by collagen in the presence or absence of PL was detected by flow cytometry [24]. The supernatant from PRP placed on immobilized collagen $\left(30 \mathrm{~min}\right.$ at $\left.37^{\circ} \mathrm{C}\right)$ was collected and centrifuged at $16,000 \mathrm{x}$ $\mathrm{g}$ to remove intact platelets. It was then incubated with a PE-conjugated CD42b antibody and FITC-conjugated annexin $\mathrm{V}$ for $20 \mathrm{~min}$ at room temperature; and fixed in a HEPES buffered saline containing $2.5 \mathrm{mM}^{\text {of }} \mathrm{CaCl}_{2}$ and $1 \%$ paraformaldehyde. MPs were first identified on particle size gated on forward scatter with a mixture of $0.5,1.0$ and $1.5 \mu \mathrm{m}$ polystyrene standard beads (BD Bioscience) and then detected for CD42b expression and annexin $\mathrm{V}$ binding.

PL on thrombus formation. Whole blood samples from healthy subjects were incubated with testing reagents for $20 \mathrm{~min}$ at $37^{\circ} \mathrm{C}$. They were then perfused over immobilized collagen (coating density: $100 \mu \mathrm{g} / \mathrm{ml}, 4^{\circ} \mathrm{C}$, overnight) at a flow rate that generated a shear stress of 60 dynes $/ \mathrm{cm}^{2}$ for $4 \mathrm{~min}$ at room temperature in an 8 channel microfluidic chamber (Cellix Mirus Nanopump ${ }^{\text {mit }}$, Dublin, Ireland). The chamber was then washed with PBS for additional 4 min. Images of thrombi formed on the collagen matrix were recorded at $400 \mathrm{x}$ magnification under an Olympus IX-81 inverted stage microscope.

Immunoblots. Washed platelets in Tyrode's buffer were treated first with a testing agent and then with collagen or/and a mixture of recombinant human IL- 6 and the extracellular domain of human IL-6 receptor- $\alpha$ (IL-6-sIL-6 $\alpha$ ). They were solubilized with a 10X hypotonic lysis buffer (120 mM Tris, $36 \mathrm{mM}$ EDTA, and 10\% Triton X-100, pH 7.5) in the presence of a cocktail of protease and phosphatase inhibitors (Sigma Aldrich). Platelet lysates were centrifuged at $13,000 \mathrm{xg}$ for $15 \mathrm{~min}$ at $4^{\circ} \mathrm{C}$ to obtain the supernatant, which was separated on $4-12 \%$ gradient SDS polyacrylamide gel electrophoresis (PAGE) and probed for phosphorylated and total JAK2, STAT3, Syk, and PLC $\gamma 2$ with specific antibodies.

Effect of PL on ROS production. Three techniques were used to detect ROS production and its impact on PL activity in collagen treated platelets. First, intracellular ROS was measured by flow cytometry using a cell permeable dye DCFH-DA (Sigma Aldrich), which remains nonfluorescent until the acetate groups are removed by intracellular esterases upon oxidative stress. The dye probe primarily detects $\mathrm{HO}$; ONOO-, $\mathrm{ROO}$; and $\mathrm{H}_{2} \mathrm{O}_{2}$ species. PRP (150 $\left.\mu \mathrm{l}\right)$ was diluted in $450 \mu \mathrm{l}$ of $\mathrm{Ca}_{2}{ }^{+}$-free HEPES buffered Tyrode's $(138 \mathrm{mM} \mathrm{NaCl}, 5.5 \mathrm{mM}$ glucose, 10 mM HEPES, $12 \mathrm{mM} \mathrm{NaHCO}_{3}, 2.9 \mathrm{mM} \mathrm{KCl}, 0.4 \mathrm{mM} \mathrm{NaH}_{2} \mathrm{PO}_{4}, 0.4 \mathrm{mM} \mathrm{MgCl}_{2}$, and $0.1 \%$ BSA, pH 7.2) and incubated with $10 \mu \mathrm{M}$ of DCFH-DA (final concentration) for $30 \mathrm{~min}$ at $37^{\circ} \mathrm{C}$. The dye-labeled platelets were analyzed after being treated with $100 \mu \mathrm{M}$ of PL and/or $10 \mu \mathrm{g} / \mathrm{ml}$ of collagen for $20 \mathrm{~min}$ at $37^{\circ} \mathrm{C}$. For data validation, the ROS probe CellROX (Life technologies, Grand Island, NY) that detects a similar set of oxidants as DCFH-DA was also tested.

Second, to measure free GSH in platelets, platelets in PRP were normalized to $250,000 / \mu \mathrm{l}$ with platelet-poor plasma and divided into 3 groups, each containing $7.5 \times 10^{7}$ platelets. PRP in two groups were treated with either $100 \mu \mathrm{M}$ of PL or $10 \mu \mathrm{g} / \mathrm{ml}$ of collagen (final concentrations) for 10 min without stirring. PRP in the third group was left untreated to set a baseline. The treated PRP was incubated with $10 \mathrm{mM}$ of freshly prepared NEM for $60 \mathrm{~min}$ at $37^{\circ} \mathrm{C}$ to block free GSH on and in platelets. The NEM alkylated platelets were quickly frozen at $-80^{\circ} \mathrm{C}$, 
thawed on ice and sonicated using a Thermo Fisher Scientific Sonic Dismembrator. The homogenized samples were mixed with isotopically labeled GSH (Sigma Aldrich) internal standard. Proteins were precipitated with methanol and the supernatant was dried by Speed-Vac. Disulfide bonded GSH was reduced by $10 \mathrm{mM}$ DTT and newly released free GSH further alkylated by NEM. Total GSH was analyzed using liquid chromatography-tandem mass spectrometry with multiple reaction monitoring (LC-MS/MS-MRM) on an AB Sciex QTrap 6500 mass spectrometer coupled to a Waters Ultra Performance Liquid Chromatographer with Cortex C18 column. The percent of free GSH was calculated by dividing free GSH with total GSH.

Third, to examine a role of ROS production in PL-mediated inhibition, platelets were preincubated with either $20 \mu \mathrm{M}$ of cell non-permeable GSH or $0.5 \mathrm{mM}$ of cell permeable L-Cysteine for $15 \mathrm{~min}$ at $37^{\circ} \mathrm{C}$ to quench the intracellular and extracellular ROS before being sequentially treated with PL and collagen. The reduced nicotinamide adenine dinucleotide phosphate (NADPH) oxidase inhibitor Apocynin was also similarly tested.

PL derivatives. All reactions were carried out under a nitrogen atmosphere in flame-dried glassware except for the hydrogenation reaction. Dichloromethane was purified by passage through activated alumina (solvent purification system). $1 \mathrm{H}$ and 13C NMR spectrum were recorded on INOVA-500. $1 \mathrm{H}$ NMR chemical shifts are reported as $\delta$ values in ppm relative to $\mathrm{CDCl} 3$ (7.26 ppm), coupling constants $(\mathrm{J})$ are reported in Hertz $(\mathrm{Hz})$, and multiplicity follows convention. Unless indicated otherwise, deuterochloroform $(\mathrm{CDCl} 3)$ served as an internal standard $(77.2 \mathrm{ppm})$ for all $13 \mathrm{C}$ spectra. Flash column chromatography was performed using $60 \AA$ Silica Gel (230-400 mesh) as a stationary phase using a gradient solvent system. Mass spectra were obtained at the center for Chemical Characterization and Analysis (Texas A\&M University). Thin layer chromatography (TLC) was performed using silica gel 60 F254 coated glass-back TLC plates.

To generate compound $1(\mathrm{C} 1)$, a mixture of piperlongumine $(30 \mathrm{mg}, 0.095 \mathrm{mmol}$ ) and 10 $\mathrm{mg}$ of $\mathrm{Pd} / \mathrm{C}$ ( $10 \mathrm{wt} . \% \mathrm{Pd} / \mathrm{C}, 0.0094 \mathrm{mmol}, 1 \%$ equiv) in $10 \mathrm{~mL}$ of EtOAc under $\mathrm{H} 2$ was stirred at $20^{\circ} \mathrm{C}$ for $2 \mathrm{~h}$, then was filtered through to a short celite pad. The pad was washed with $10 \mathrm{ml}$ of EtOAc. The solution was concentrated and the crude product was purified by a silica gel flash chromatography (Hexanes:EtOAc $=1: 1$ ) to give the desired product as a colorless oil (29 mg, 95\%).

Compound $2(\mathrm{C} 2)$ was prepared as a potential probe compound to aid in the identification of the biological target of PL and to provide structure-activity relationships (SAR). C2 has an alkyne group (a latent functional group for further derivatization) that can be used to add additional groups, such as biotin or a fluorophore) that can be used to identify the mode of action of PL. Selective cleavage of the methyl ether at the 4-position of the aromatic ring of PL was achieved using aluminum trichloride in dichloromethane at $0^{\circ} \mathrm{C}$ to give an intermediate compound in a high yield. Alkylation of the phenol with propargyl bromide produced the alkynyl derivative $\mathrm{C} 2$ in $67 \%$ yield. Hydrogenation of PL in ethyl acetate gave derivative compound 1 in $95 \%$ yield and provided an additional compound for SAR.

Statistical analyses. Categorical (frequency) variables were expressed as percentages and continuous variables as mean \pm SEM. All quantitative data were analyzed by pair comparisons, one way or repeated measure ANOVA. A p value of less than 0.05 was considered to be statistically significant.

\section{Results}

\section{Effect of PL on collagen-induced platelet activation and aggregation}

PL dose-dependently blocked collagen-induced platelet aggregation with a maximal inhibition achieved at $100 \mu \mathrm{M}$ (Fig 1A). This inhibitory effect was observed at the subthreshold (2 $\mu \mathrm{g} / \mathrm{ml})$ 
A. Collagen $5 \mu \mathrm{g} / \mathrm{ml}$

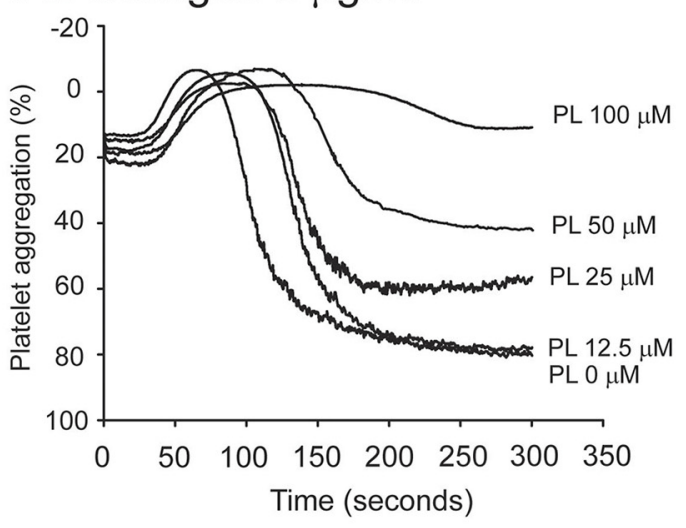

B

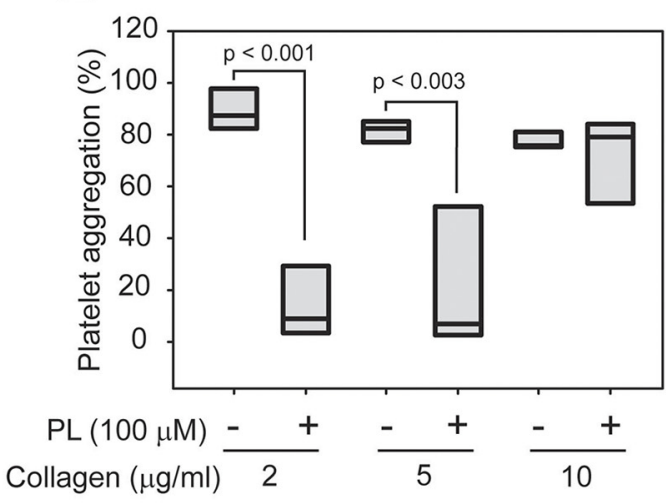

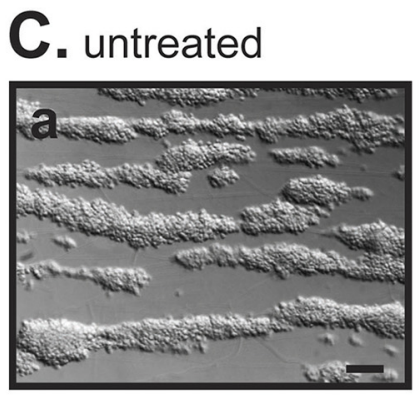

$\mathrm{PL} 50 \mu \mathrm{M}$

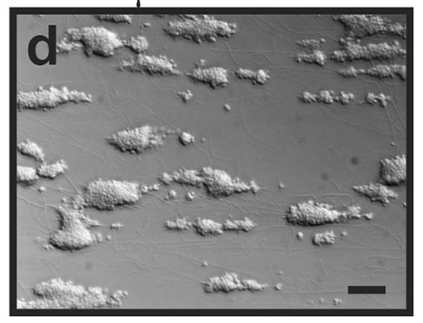

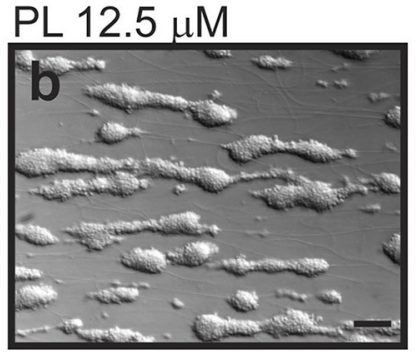
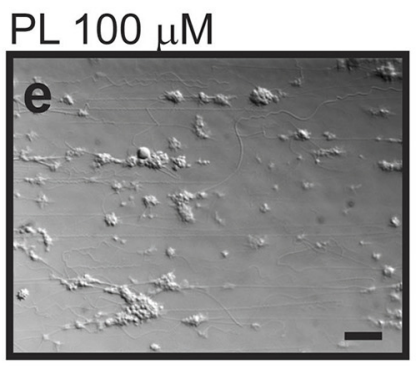
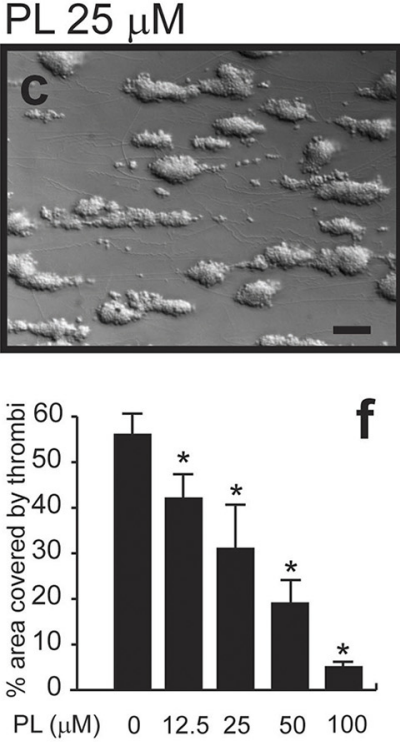
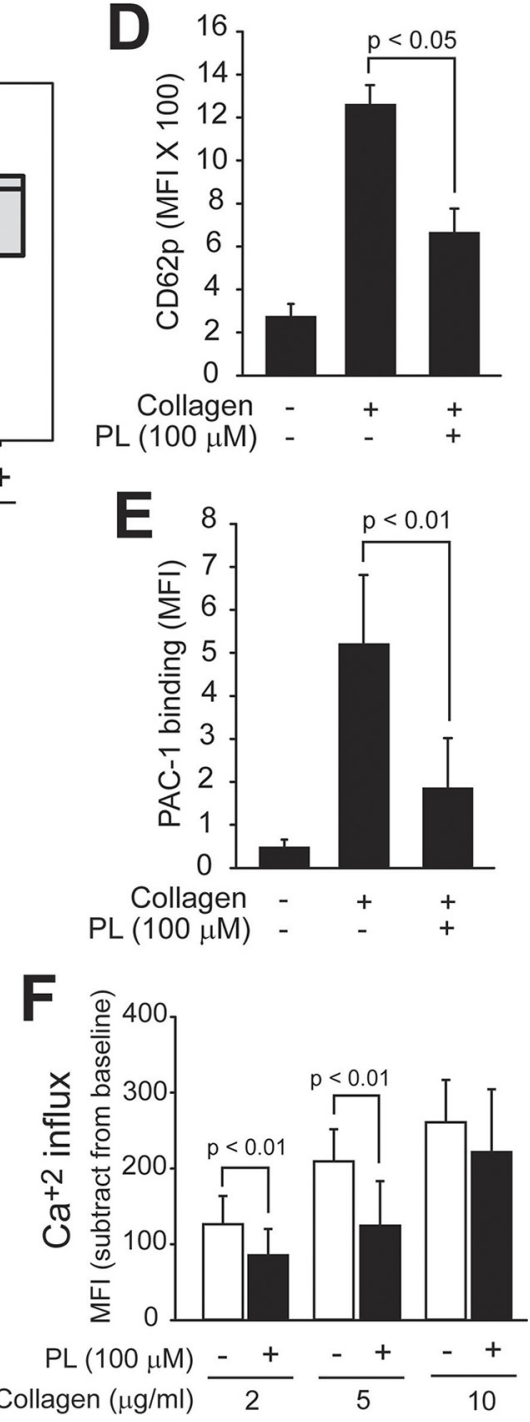

Fig 1. PL inhibited collagen-induced platelet reactivity. (A) Platelets were induced to aggregate by $5 \mu \mathrm{g} / \mathrm{ml}$ of collagen in the presence of increasing concentrations of PL (a representative of 10 separate experiments). (B) PL blocked platelet aggregation induced by low doses, but not a maximal dose of collagen $(n=10$, paired $t$ test). (C) PL blocked the thrombus formation of platelets on the collagen matrix under flow conditions (panels a-e are representative images [bar $=100 \mu \mathrm{m}$ ] and panel $\mathrm{f}$ is a summary of 6 separate experiments, repeated measures ANOVA, ${ }^{*} p<0.01$ compared untreated platelets). PL blocked collagen-induced CD62p expression (D), PAC-1 binding (E), and calcium influx (F). Data presented in panels D-F were obtained from 6-8 donors and analyzed by ANOVA (panels D-E) and $t$ test (panel F).

doi:10.1371/journal.pone.0143964.g001

and high $(5 \mu \mathrm{g} / \mathrm{ml})$ concentration of collagen, but not at a maximal concentration of $10 \mu \mathrm{g} / \mathrm{ml}$ (Fig 1B). PL was equally effective in blocking platelet thrombus formation on immobilized collagen under an arterial shear stress of 60 dynes $/ \mathrm{cm}^{2}$ (Fig 1C). Consistent with its effect on platelet aggregation and thrombus formation, PL partially blocked the collagen-induced expression of CD62p (Fig 1D), binding of PAC-1, an antibody that specifically recognizes the activated form of the integrin $\alpha \operatorname{IIb} \beta 3$ (Fig 1E) and calcium influx (Fig 1F). These inhibitory activities of PL were not mediated by inducing receptor shedding because surface densities of GP VI (Fig 2A), which were reduced by collagen stimulation, and the integrin $\alpha I I b \beta_{3}$ (Fig 2B) were not reduced by the PL treatment. As control, collagen induced a significant increase in the expression of integrin $\alpha I I b \beta_{3}$. PL also inhibited platelet aggregation induced by CRP (Fig 
A

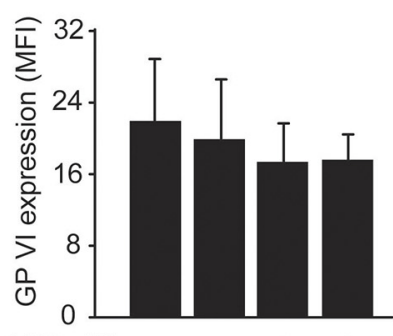

$\mathrm{PL}(100 \mu \mathrm{M})-\quad-\quad+\quad+$ Collagen $(5 \mu \mathrm{g} / \mathrm{ml})-++\quad+$

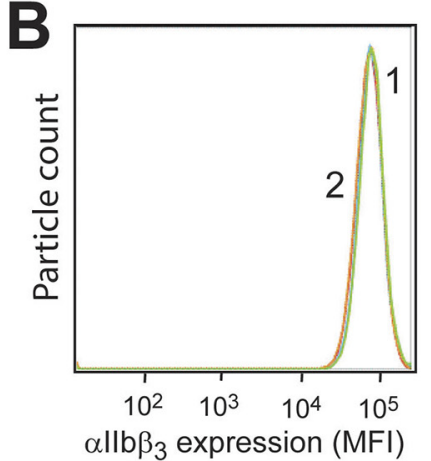

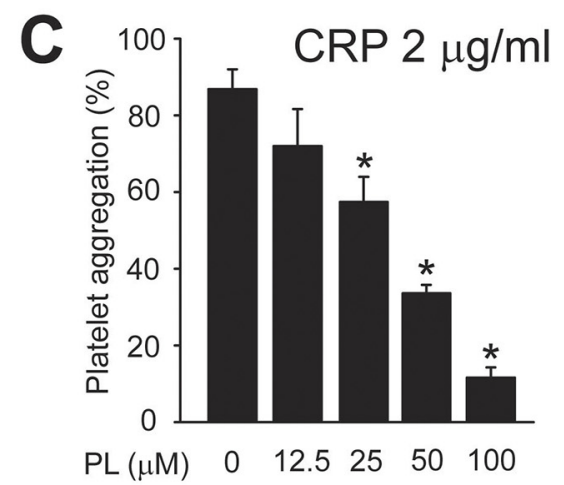
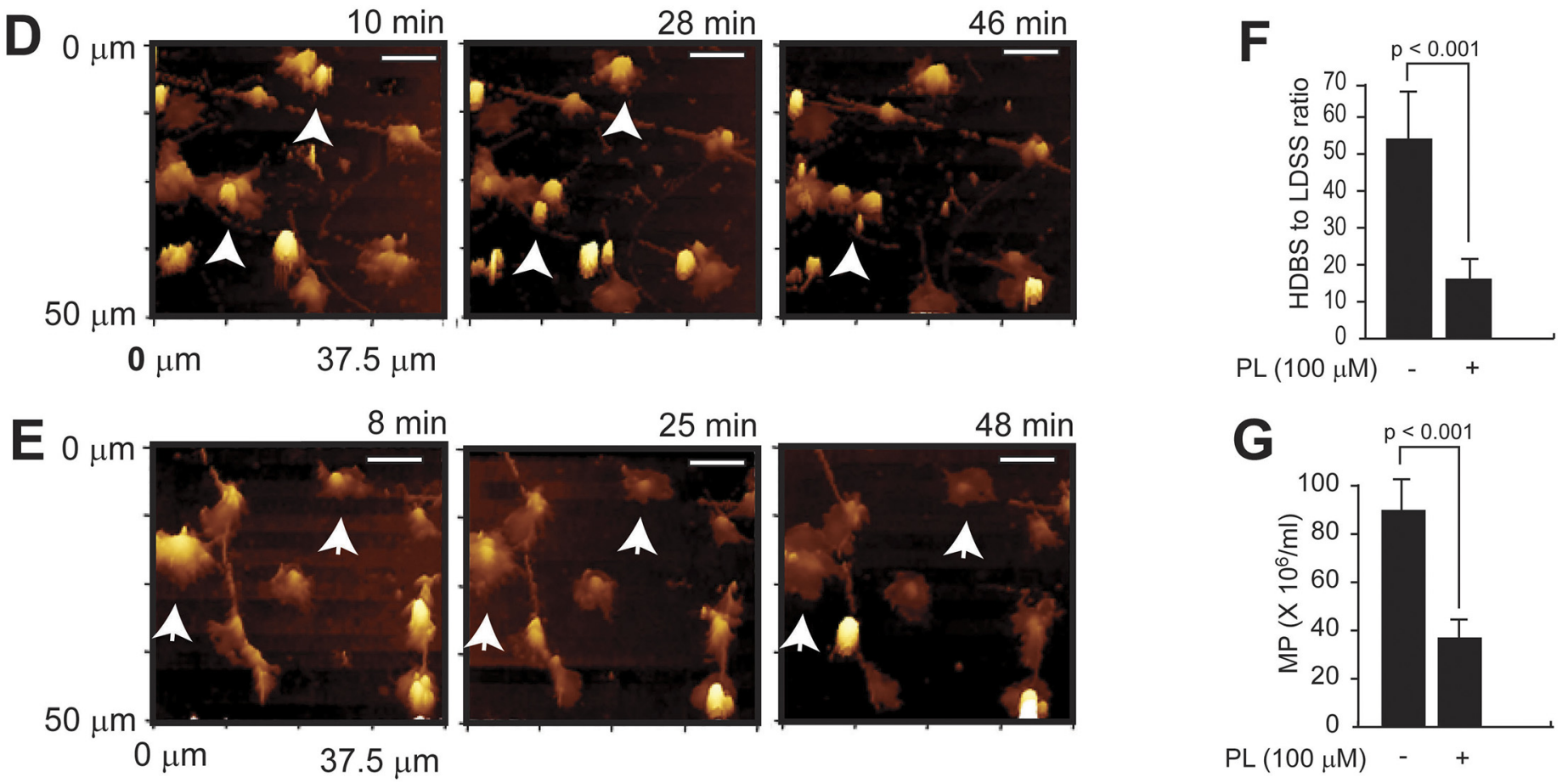

Fig 2. Effects of PL on collagen-induced platelet activation, morphological transition, and microvesiculation. PRP was stimulated with $5 \mu \mathrm{g} / \mathrm{ml}$ of collagen in the presence and absence of $100 \mu \mathrm{M}$ PL. Surface expressions of GP VI (A, $n=5$, ANOVA) and $\alpha$ llbBß 3 (B, $n=6,{ }^{*} p<0.001 \mathrm{compared}$ to $P L$ treated platelets) were measured by flow cytometry using specific monoclonal antibodies. (C) PL dose-dependently blocked CRP-induced platelet aggregation $(n=6$, ANOVA). The morphological transition of adherent platelets on the collagen matrix was monitored by HPICM over $\sim 60$ min (D \& E, bar $=10 \mu \mathrm{m})$. A ratio of HDBS to LDSS platelets was calculated $\left(\mathrm{F}, \mathrm{n}=6\right.$, paired $t$ test) and $C D 42 \mathrm{~b}^{+}$and annexin $\mathrm{V}^{+}$platelet microparticles were quantified (G, $\mathrm{n}=6$, paired $t$ test).

doi:10.1371/journal.pone.0143964.g002

2C), which specifically targets GP VI, one of two collagen receptors on platelets. In contrast, PL had no effect on collagen-induced aggregation of platelets from mice deficient in platelet STAT3 (S1 Fig). Aggregation of human platelets by ADP $(5 \mu \mathrm{M})$ and TRAP $(50 \mu \mathrm{M})$, pretreated with PL also induced aggregation at a level comparable to $5 \mu \mathrm{g} / \mathrm{ml}$ of collagen (S2 Fig).

Effect of PL on collagen-induced microparticle production. We previously used a novel HPICM technology to monitor ADP-induced morphological changes and microvesiculation of adherent platelets on immobilized fibrinogen [24]. This technology was modified to monitor real time morphological transformations and microparticle production of platelets on immobilized collagen. As shown in Fig 2D, platelets adherent to collagen presented as predominantly high density bubble shapes (HDBS), which we previously found to be sensitive to agonist- 
induced microvesiculation [24]. In contrast, many of the PL-treated platelets underwent a reverse transformation from a high-density bubble shape to a low-density spread shape (LDSS, Fig 2E), resulting in a significantly reduced ratio of HDBS to LDSS platelets (Fig 2F) and a reduced production of platelet microparticles (Fig 2G). Together, data presented in Figs 1 and 2 demonstrated an inhibitory activity of PL towards collagen-induced platelet activation and aggregation.

Effect of PL on collagen-induced STAT3 activation. We have recently shown that PL potently inhibits STAT3 activation in cancer cells [19] and that STAT3 non-transcriptionally regulates collagen-induced platelet activation/aggregation by facilitating an interaction between the kinase Syk and the substrate PLC $\gamma 2$ [22]. These results led us to hypothesize that PL targets STAT3 to block collagen-induced platelet reactivity. Here, we provide several lines of experimental evidence to support the hypothesis. First, PL blocked the tyrosine phosphorylation of JAK2 (Fig 3A) and STAT3 (Fig 3B) in platelets stimulated with collagen. As a control, STAT3 phosphorylation induced by a complex of IL-6-sIL-6R $\alpha$, which signals through the JAK2-STAT3 pathway in eliciting an acute phase reaction, was also blocked by PL (Fig 3B). Second, PL was significantly less effective in platelets pretreated with the STAT3 inhibitor STA21 (Fig 3C), whereas its effect was additive to that of the transcription inhibitor Actinomycin D (Fig 3D). The latter result suggests that PL acted independent of (mitochondrial) transcription in platelets. Third, the JAK2 inhibitor AG490 dose-dependently blocked collageninduced platelet aggregation (Fig $3 \mathrm{E}$ ) and thrombus formation on a collagen matrix under an arterial fluid shear stress of 60 dynes $/ \mathrm{cm}^{2}$ (Fig 3F).

While PL did not inhibit the tyrosine phosphorylation of Syk (Fig 4A), it was effective in blocking PLC $\gamma 2$ phosphorylation (Fig 4B) in collagen-stimulated platelets. This regulatory profile of PL is identical to that of STAT3 inhibitors on platelets [22], suggesting that PL does not directly inhibit GP VI-mediated signaling, but disrupts the phosphorylation and subsequent dimerization of STAT3, which are necessary to accelerate or enhance the activity of Syk kinase towards the substrate PLC $\gamma 2$. Consistent with this notion, the Syk inhibitor SykII inhibited collagen-induced platelet aggregation in synergy with the inhibitory activity of PL (Fig 4C).

Differential ROS production in platelets treated with PL or collagen. Collagen has been reported to induce ROS release from platelets [18] and several varieties of ROS are known to activate platelets [25], suggesting that ROS is stimulatory to platelets. However, PL has been shown to induce ROS production in cancerous, but not normal cells by binding and down-regulating the activities of GSTP1 and carbonyl reductase 1 CBR1 [11]. These contradictory observations prompted us to examine whether PL induces ROS in platelets. PL at $100 \mu \mathrm{M}$ that maximally blocked collagen-induced platelet activation and aggregation (Fig 1) induced the release of ROS in platelets as detected by flow cytometry using DCFH-DA and CellRox Red probes (Fig 5A). GSTP1 and CBR1 were also detected in platelets at levels that were not altered by collagen-or/and IL-6-sIL-6 $\alpha$ stimulations (S3 Fig). Consistent with previous reports [18], collagen induced platelet production of ROS in a dose dependent manner and its effect was additive to that of PL (Fig 5B). This potent effect of PL on ROS production was further validated by a significant reduction of free GSH in platelets treated with PL, but not with collagen (Fig 5C). However, quenching ROS with $20 \mu \mathrm{M}$ of cell non-permeable GSH (Fig 5D) or 0.5 $\mathrm{mM}$ of cell permeable L-Cysteine (Fig 5E) did not reverse the inhibitory effects of PL on collagen-induced platelet aggregation, even though both anti-oxidants were used at concentrations significantly higher than their baseline plasma levels [26;27]. GSH also failed to reverse PLinduced reduction of PAC-1 binding to collagen-stimulated platelets (Fig 5G). Apocynin, which is an inhibitor of the reduced nicotinamide adenine dinucleotide phosphate (NADPH) oxidase and reported to block collagen-induced ROS production in platelets [18] did not alter the effect of PL on collagen-induced platelet aggregation (Fig 5H). 


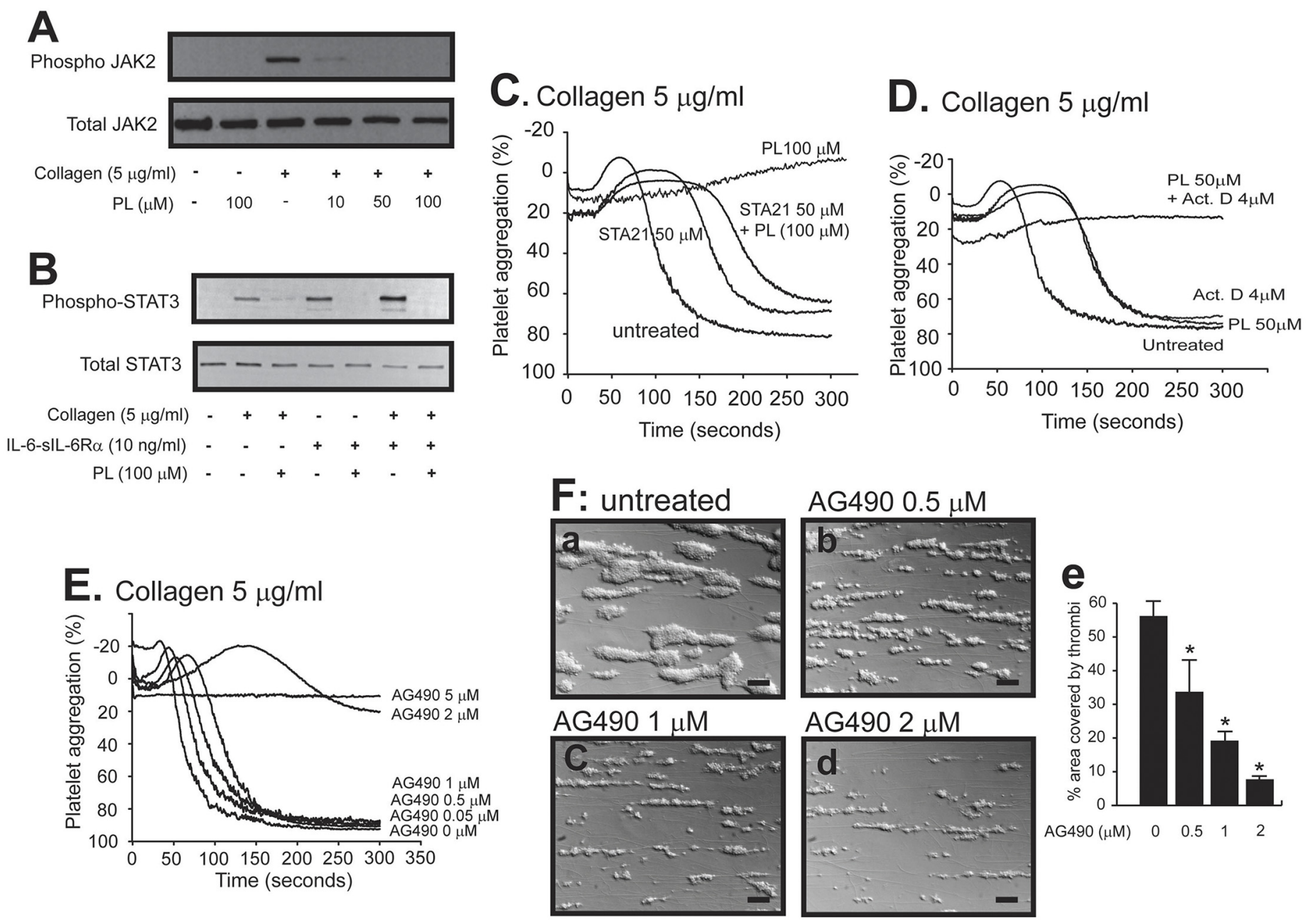

Fig 3. PL blocked JAK2-STAT3 activation. Lysates of platelets stimulated with collagen in the presence of PL were probed for total and phospho-JAK2 (A) and STAT3 (B). STAT3 phosphorylation was also probed in platelets treated with a complex of IL-6-sIL-6a either alone or combined with collagen as control (B). Platelet aggregation was also induced by collagen in the presence of a submaximal $50 \mu \mathrm{M}$ of PL with and without a maximal inhibitory $50 \mu \mathrm{M}$ of STA21 (C, a representative of 6 experiments) or actinomycin $D(D$, a representative of 6 experiments). Platelets treated with an increasing concentration of the JAK2 inhibitor AG490 were induced to aggregate $(E)$ and to form thrombi on immobilized collagen under flow condition ( $F$, bar $=100 \mu \mathrm{m}$, the panel e summaries results from 3 experiments, repeated measure ANOVA, $\left.{ }^{*} p<0.01\right)$.

doi:10.1371/journal.pone.0143964.g003

Generation and testing of synthetic analogs. The diverse effects of PL on cancer cells and platelets may result from different structures and chemical moieties. To examine the role of specific chemical moieties in blocking platelet reactivity to collagen, we synthesized two PL analogs (Fig 6A) through hydrogeneration [3] and by introducing a terminal alkyne [11] at a site away from the possible "bioactivity bearing" functional groups (compound $1 \& 2$ ). The two derivatives were found to be active in blocking platelet aggregation induced by $2 \mu \mathrm{g} / \mathrm{ml}$ (Fig 6B and $6 \mathrm{D}$ ), but not at $5 \mu \mathrm{g} / \mathrm{ml}$ of collagen (data not shown).

\section{Discussion}

PL has been reported to be inhibitory to several major platelet agonists. Here, we have specifically characterized inhibitory effects of PL on collagen-induced platelet reactivity (Figs 1 and 2) to explore the influence of PL on the platelet JAK2- STAT3 pathway. Our findings are consistent with previous reports $[13 ; 14]$. We have also made several new observations that define the 
A

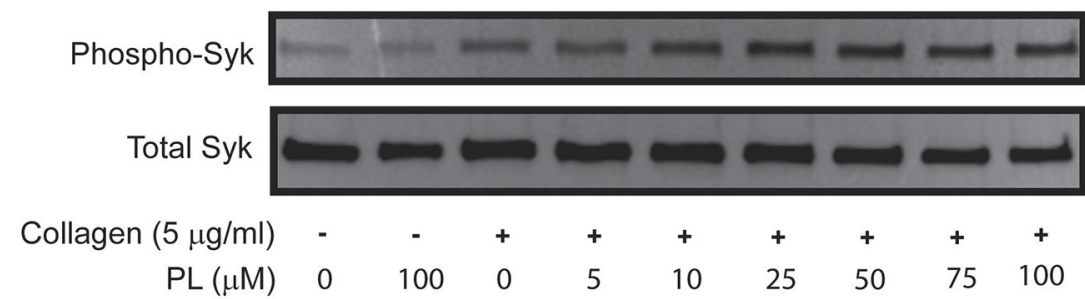

\section{B}

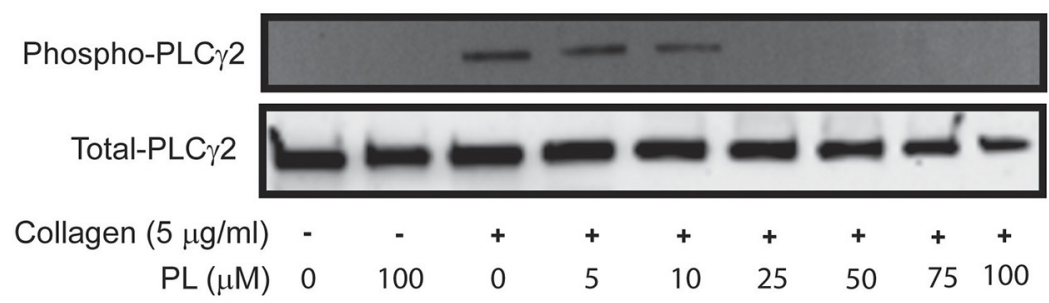

\section{Collagen $5 \mu \mathrm{g} / \mathrm{ml}$}

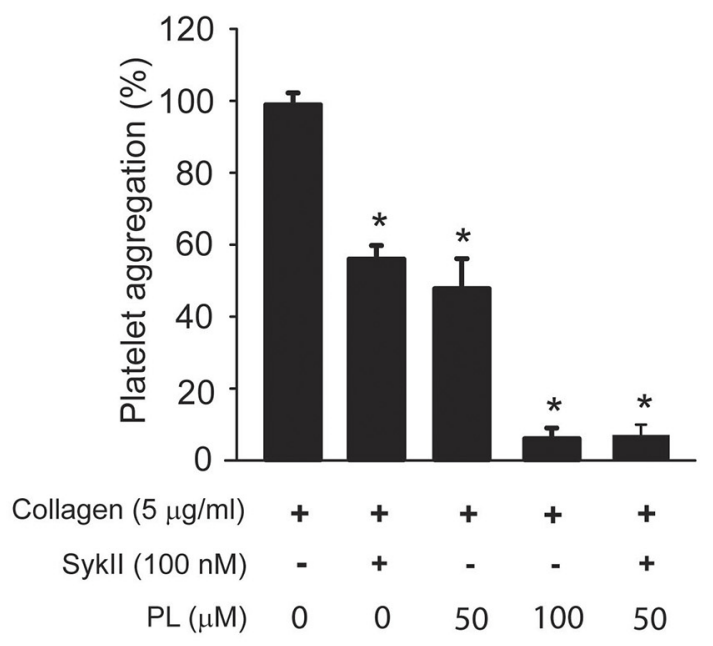

Fig 4. PL effect on collagen-GP VI signaling. Lysates of platelets treated with collagen in the presence of PL were probed for total and phosphorylated Syk (A) and PLCY2 (B). (C) Platelets were first incubated with Sykll for 10 min followed by additional 10 min incubation with PL before being stimulated with collagen $\left(n=3\right.$, repeated measures ANOVA, $\left.{ }^{*} p<0.01\right)$.

doi:10.1371/journal.pone.0143964.g004

mechanism by which PL inhibits collagen-induced platelet activation and provide new information regarding the differential effects of ROS on platelet reactivity to collagen.

First, PL inhibited collagen-induced platelet reactivity primarily by blocking the activation of JAK2 and STAT3. This conclusion is supported by several lines of experimental evidence presented in Figs $3 \& 4$. In nucleated cells, tyrosine phosphorylated STAT3 dimerizes to be more efficiently translocated into the nucleus to regulate the transcription of multiple genes associated with the acute phase reaction [28-31]. We have recently shown that a STAT3 dimer enhances collagen-induced signaling in platelets by serving as a protein scaffold for Syk and PLC 22 [22] and PL prevents this critical dimerization by preventing JAK2-mediated STAT2 activation [19]. Furthermore, PL did not directly inhibit collagen-induced Syk phosphorylation, but did block the activation of its substrate PLC $\gamma 2$. This regulatory profile is consistent with the notion that a phosphorylated STAT3 dimer serving as a protein scaffold linking the kinase Syk to the substrate PLC $\gamma 2$ in the GP IV signal pathway. Furthermore, the JAK2 inhibitor AG-490 (Tyrphostin B42), which has no effect on the kinases Lyn, Syk and Src involved in GP VI signaling, also blocked collagen-induced platelet aggregation and thrombus formation under flow conditions (Fig 3E and 3F). Together, these data suggest that PL directly prevents STAT3 dimerization and indirectly by blocking JAK2 activation.

Second, both PL and collagen induced ROS production in platelets (Fig 5A-5C), but PL's inhibitory activity on collagen-induced platelet activation was not affected by the ROS (Fig 5D-5G). The results raise two interesting questions. The first regards the previous reports that PL induces ROS production by inhibiting GSTP1 activity specifically in cancerous, but not normal cells, leading to ROS-mediated apoptosis [3;11]. Platelets treated with PL did not undergo apoptosis as they remained aggregatable in response to high doses of collagen (Fig 1B), ADP (S1 Fig) and TRAP (S1 Fig). They also had a reduced rate of microvesiculation (Fig 2E-2H). 
A

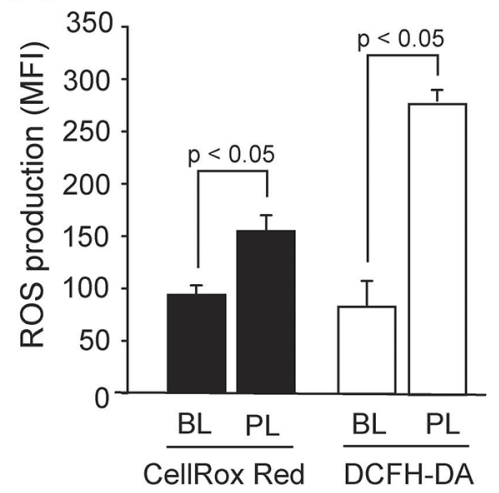

D
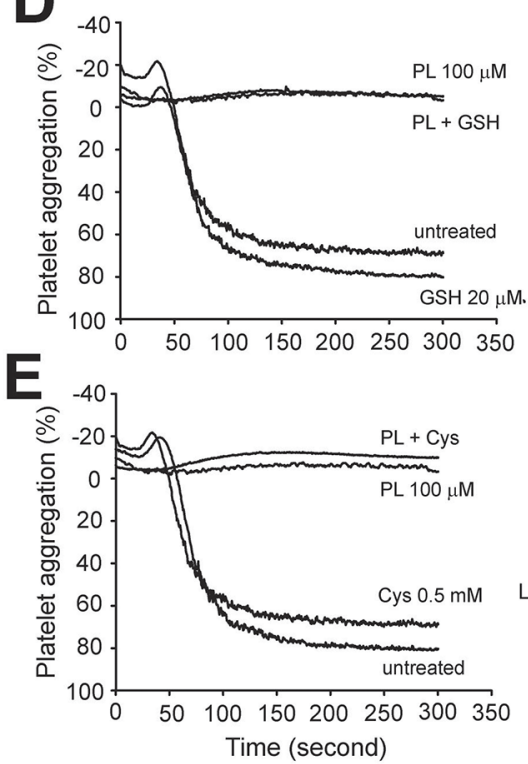

B

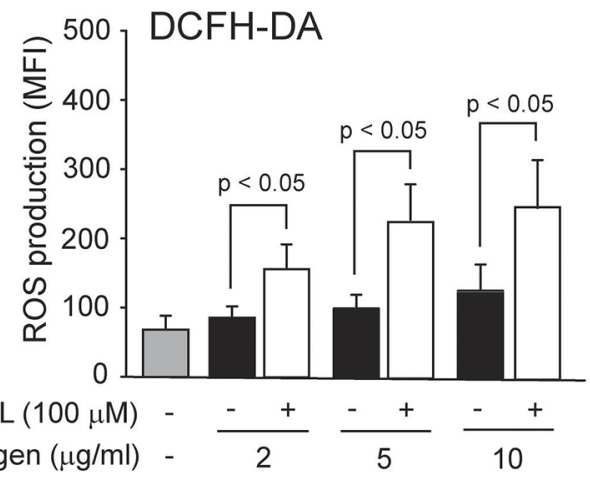

C

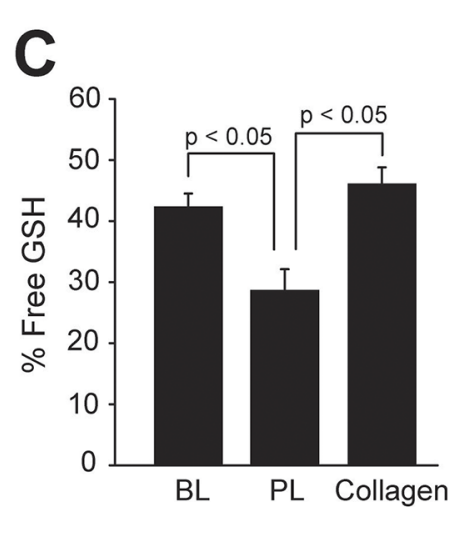

Collagen $(\mu \mathrm{g} / \mathrm{ml})-\frac{1}{n} \quad 2 \quad 5$
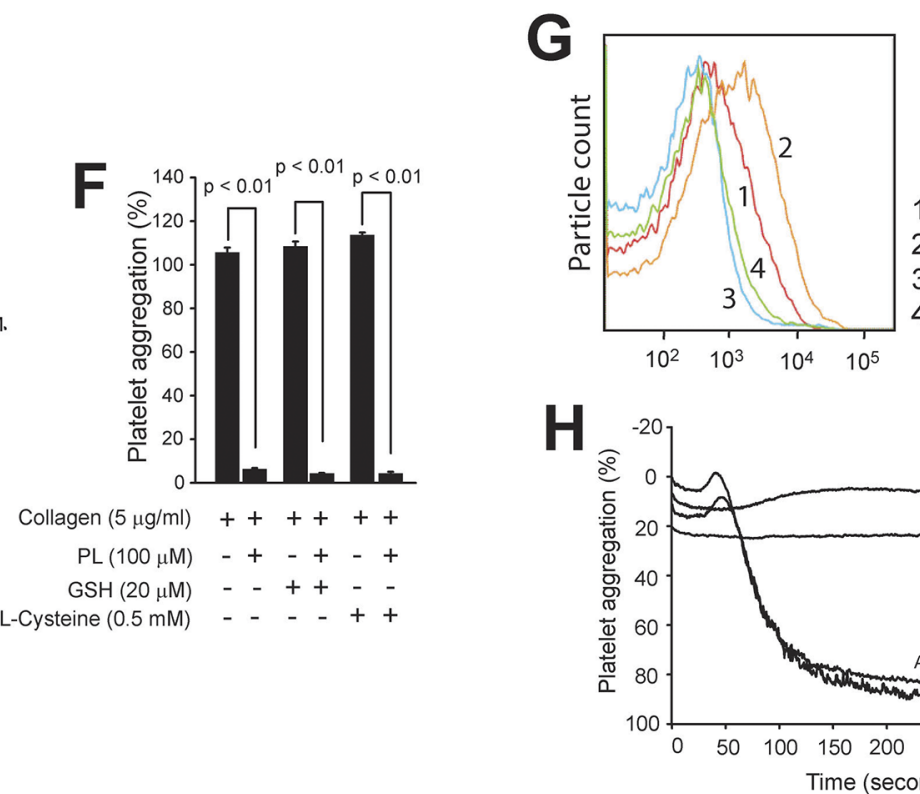

1: Untreated

2: Collagen $5 \mu \mathrm{g} / \mathrm{ml}$

3: Collagen + PL $100 \mu \mathrm{M}$

4: Collagen + PL + GSH $20 \mu \mathrm{M}$

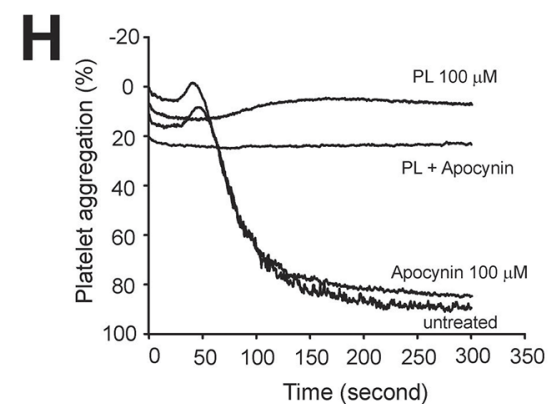

Fig 5. PL-induced ROS production and activity. Platelets in PRP were labeled with either CellROX Red or DCFH-DA for 30 min at $37^{\circ} \mathrm{C}$ and treated with either100 $\mu \mathrm{M}$ of $\mathrm{PL}$ or vehicle control (BL) for additional $10 \mathrm{~min}$. ROS production was measured in platelets by flow cytometry (A, $n=10$, paired $t$ test). ROS production was also measured in platelets stimulated with various doses of collagen in the presence and absence of $P L(B, n=6, p a i r e d t$ test). Free $G S H$ was measured by mass spectrometry in resting platelets and those treated with either PL or collagen for 10 min at $37^{\circ} \mathrm{C}(C, n=3$, one way ANOVA). Collagen-induced aggregation was recorded in platelets preincubated with either GSH (D) or L-cysteine before treatment with $100 \mu \mathrm{M}$ PL (E). Platelets treated with GSH or L-cysteine without PL were tested as controls (panel F summaries data from 3 experiments). Platelets were treated with collagen, $\mathrm{PL}$, and PL plus GSH for $10 \mathrm{~min}$ at $37^{\circ} \mathrm{C}$. PAC- 1 binding was then detected by flow cytometry (G, a representative of 3 experiments). PRP was incubated with Apocynin for $10 \mathrm{~min}$ at $37^{\circ} \mathrm{C}$ followed by additional $10 \mathrm{~min}$ of incubation with $100 \mu \mathrm{M}$ of PL. Collagen-induced platelet aggregation was then recorded (H, a representative of 3 experiments).

doi:10.1371/journal.pone.0143964.g005

The second question regards the impact of ROS on platelet reactivity. The inhibitory effects of PL on collagen-induced platelet reactivity was not affected by cell permeable and non-permeable reducing agents that quench extracellular and intracellular oxidants; and by a NADPH oxidase inhibitor (Fig 5D-5G), which blocked collagen-and thrombin-induced ROS production in platelets $[17 ; 18]$. The finding strongly suggests that PL and collagen induce the release of different oxidants that have differential effects on platelets. For example, PL induces cancer cells to produce nitric oxide [11], which is a well-known platelet inhibitor [32]. Our finding also differs from the reported effect of the GSH precursor N-acetyl-L-cysteine on eliminating PL's effect on cancer cells [11], implying that PL acts differently in cancer cells and in platelets. 
A<smiles>COc1cc(/C=C/C(=O)N2CCC=CC2=O)cc(OC)c1OC</smiles>

Compound 1 (C1)<smiles>COc1cc(CCC(=O)N2CCCCC2=O)cc(OC)c1OC</smiles>

\section{Compound 2 (C2)}<smiles>C#CCOc1c(OC)cc(/C=C/C(=O)N2CCC=CC2=O)cc1OC</smiles>

B. Collagen $(2 \mu \mathrm{g} / \mathrm{ml})$

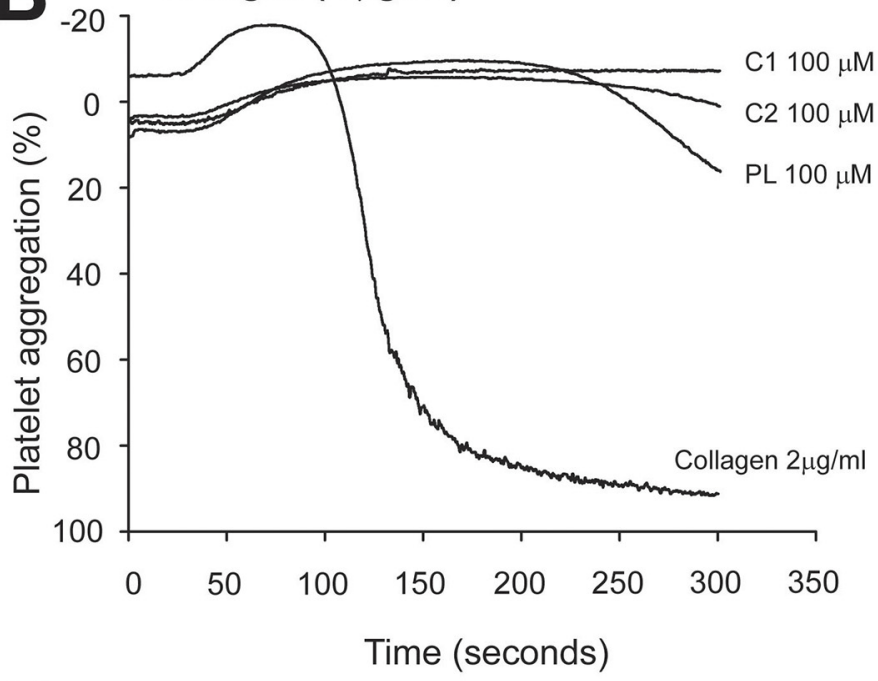

D

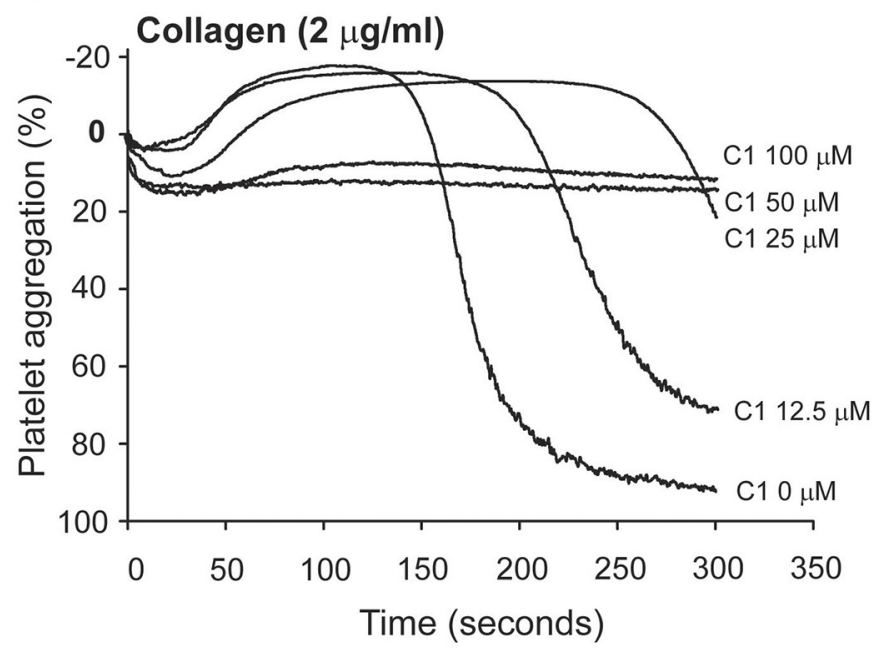

Fig 6. Effects of PL analogs on collagen-induced platelet aggregation. (A) PL and structural derivatives compound 1 (C1) and compound 2 (C2). (B) PRP was incubated with $\mathrm{PL}, \mathrm{C} 1$ or $\mathrm{C} 2$ for $15 \mathrm{~min}$ at $37^{\circ} \mathrm{C}$ and then induced to aggregate by $2 \mu \mathrm{g} / \mathrm{ml}$ of collagen (a representative of 10 experiments). (C \& D) $\mathrm{C} 1$ and $\mathrm{C} 2$ were also tested at different doses for their impact on collagen-induced platelet aggregation.

doi:10.1371/journal.pone.0143964.g006

Studying these differential effects on drug-induced oxidative stress may uncover new mechanisms of regulating platelet functions by selective oxidants.

Third, we made and tested two PL analogs with specific structure modifications. These analogs are designed to help differentiate the contributions of specific structures on inhibitory activity of PL in collagen-induced platelet reactivity. The double bonds C3-C4 and C7-C8 in $\mathrm{PL}$ were reduced in compound 1 to make the analog less reactive. It has also been shown that the electrophilicity of the C2-C3 olefin is critical for the apoptotic effects of PL on cancer cells, whereas analogs lacking a reactive C7-C8 olefin induce intracellular ROS, but markedly reduced cell death [3]. In contrast, compound 2 was designed as a potential probe to identify biological targets of PL and to provide structure-activity relationships. However, both derivatives are equally active in blocking platelet reactivity to the low dose of collagen (Fig 6). 
In summary, we have shown that PL inhibits collagen-induced platelet activation, aggregation, and thrombus formation by primarily blocking JAK2-STAT3 phosphorylation, reducing the ability of STAT3 to serve as a protein scaffold for linking Syk to PLC 2 . We further show that, while PL induces ROS in platelets, its inhibitory activity towards collagen-induced platelet activation was not affected by ROS, suggesting that ROS have differential effects on platelet reactivity.

\section{Supporting Information}

S1 Fig. Citrated PRP from STAT3 ${ }^{-/-}$and littermate control mice were preincubated with either PL and the vehicle DMSO for $10 \mathrm{~min}$ at $37^{\circ} \mathrm{C}$ and then stimulated with $0.75 \mu \mathrm{g} / \mathrm{ml}$ of fibrillary type I collagen. Platelet aggregation was monitored for $10 \mathrm{~min}$ at $37^{\circ} \mathrm{C}$. We have previously shown that, at this dose of collagen, the collagen-induced aggregation of platelet from $\mathrm{STAT3}^{-/-}$was significantly reduced as compared to control platelets (22). Here, we further show that PL was not active in blocking collagen-induced aggregation of platelets from the $\mathrm{STAT}^{-/-}$mice ( $\mathrm{n}=8$ mice/group, paired t test). (JPG)

S2 Fig. Platelet aggregation induced by $5 \mu \mathrm{M}$ of ADP (A) or $50 \mu \mathrm{M}$ of TRAP (B) was not blocked by PL.

S3 Fig. Expression of GSTP-1 and CBR-1 in platelets detected by immunoblots. (JPG)

\section{Acknowledgments}

We thank the Vice President for Research, College of Science, and Department of Chemistry at Texas A\&M University for seed funding to the Natural Products LINCHPIN Laboratory.

\section{Author Contributions}

Conceived and designed the experiments: DJT DR XF JZ JFD. Performed the experiments: HY KLH YT UB XW ZZ MZ. Analyzed the data: HY KLH YT UB XW YZ. Contributed reagents/ materials/analysis tools: KH. Wrote the paper: DJT DR XF JZ JFD.

\section{References}

1. Kumar S, Kamboj J, Suman, Sharma S. 2011. Overview for various aspects of the health benefits of Piper longum linn. fruit. J. Acupunct. Meridian. Stud. 4:134-140. doi: 10.1016/S2005-2901(11)600204 PMID: 21704957

2. Bezerra DP, Pessoa C, de Moraes MO, Saker-Neto N, Silveira ER, Costa-Lotufo LV. 2012. Overview of the therapeutic potential of piplartine (piperlongumine). Eur. J. Pharm. Sci. 48:453-463. doi: 10. 1016/j.ejps.2012.12.003 PMID: 23238172

3. Adams DJ, Dai M, Pellegrino G, Wagner BK, Stern AM, Shamji AF, et al. 2012. Synthesis, cellular evaluation, and mechanism of action of piperlongumine analogs. Proc. Natl. Acad. Sci. U.S. A. 109:15115-15120. PMID: 22949699

4. Morikawa T, Matsuda H, Yamaguchi I, Pongpiriyadacha Y, Yoshikawa M. 2004. New amides and gastroprotective constituents from the fruit of Piper chaba. Planta Med. 70:152-159. PMID: 14994194

5. Silva DR, Endo EH, Filho BP, Nakamura CV, Svidzinski TI, de SA, et al. 2009. Chemical Composition and Antimicrobial Properties of Piper ovatum Vahl. Molecules. 14:1171-1182. doi: 10.3390/ molecules14031171 PMID: 19325517

6. Lee SE, Park BS, Bayman P, Baker JL, Choi WS, Campbell BC. 2007. Suppression of ochratoxin biosynthesis by naturally occurring alkaloids. Food Addit. Contam. 24:391-397. PMID: 17454112 
7. Zhang H, Matsuda H, Nakamura S, Yoshikawa M. 2008. Effects of amide constituents from pepper on adipogenesis in 3T3-L1 cells. Bioorg. Med. Chem. Lett. 18:3272-3277. doi: 10.1016/j.bmcl.2008.04. 052 PMID: 18477507

8. Jin Z, Borjihan G, Zhao R, Sun Z, Hammond GB, Uryu T. 2009. Antihyperlipidemic compounds from the fruit of Piper longum L. Phytother. Res. 23:1194-1196. doi: 10.1002/ptr.2630 PMID: 19172581

9. Son DJ, Kim SY, Han SS, Kim CW, Kumar S, Park BS, et al. 2012. Piperlongumine inhibits atherosclerotic plaque formation and vascular smooth muscle cell proliferation by suppressing PDGF receptor signaling. Biochem. Biophys. Res. Commun. 19; 427:349-354. doi: 10.1016/j.bbrc.2012.09.061 PMID: 22995306

10. Kim KS, Kim JA, Eom SY, Lee SH, Min KR, Kim Y. 2006. Inhibitory effect of piperlonguminine on melanin production in melanoma B16 cell line by downregulation of tyrosinase expression. Pigment Cell Res. 19:90-98. PMID: 16420250

11. Raj L, Ide T, Gurkar AU, Foley M, Schenone M, Li X, et al. 2011. Selective killing of cancer cells by a small molecule targeting the stress response to ROS. Nature. 475:231-234. doi: 10.1038/nature10167 PMID: 21753854

12. Jarvius M, Fryknas M, D'Arcy P, Sun C, Rickardson L, Gullbo J, et al. 2013. Piperlongumine induces inhibition of the ubiquitin-proteasome system in cancer cells. Biochem. Biophys. Res. Commun. 431:117-123. doi: 10.1016/j.bbrc.2013.01.017 PMID: 23318177

13. Park BS, Son DJ, Choi WS, Takeoka GR, Han SO, Kim TW, et al. 2008. Antiplatelet activities of newly synthesized derivatives of piperlongumine. Phytother. Res. 22:1195-1199. doi: 10.1002/ptr.2432 PMID: 18697182

14. Park BS, Son DJ, Park YH, Kim TW, Lee SE. 2007. Antiplatelet effects of acidamides isolated from the fruits of Piper longum L. Phytomedicine. 14:853-855. PMID: 17689230

15. Iwashita M, Oka N, Ohkubo S, Saito M, Nakahata N. 2007. Piperlongumine, a constituent of Piper longum L., inhibits rabbit platelet aggregation as a thromboxane A(2) receptor antagonist. Eur. J. Pharmacol. 570:38-42. PMID: 17618620

16. Arthur JF, Gardiner EE, Kenny D, Andrews RK, Berndt MC. 2008. Platelet receptor redox regulation. Platelets. 19:1-8. doi: 10.1080/09537100701817224 PMID: 18231933

17. Begonja AJ, Gambaryan S, Geiger J, Aktas B, Pozgajova M, Nieswandt B, et al. 2005. Platelet NAD(P) $\mathrm{H}$-oxidase-generated $\mathrm{ROS}$ production regulates alphallbbeta3-integrin activation independent of the NO/cGMP pathway. Blood. 106:2757-2760. PMID: 15976180

18. Arthur JF, Qiao J, Shen Y, Davis AK, Dunne E, Berndt MC, et al. 2012. ITAM receptor-mediated generation of reactive oxygen species in human platelets occurs via Syk-dependent and Syk-independent pathways. J. Thromb. Haemost. 10:1133-1141. doi: 10.1111/j.1538-7836.2012.04734.x PMID: 22489915

19. Bharadwaj U, Eckols TK, Kolosov M, Kasembeli MM, Adam A, Torres D, et al. 2014. Drug-repositioning screening identified piperlongumine as a direct STAT3 inhibitor with potent activity against breast cancer. Oncogene (in press).

20. Mieyal JJ, Chock PB. 2012. Posttranslational modification of cysteine in redox signaling and oxidative stress: Focus on s-glutathionylation. Antioxid. Redox. Signal. 16:471-475. doi: 10.1089/ars.2011.4454 PMID: 22136616

21. Zhong Z, Wen Z, Darnell JE Jr. 1994. Stat3: a STAT family member activated by tyrosine phosphorylation in response to epidermal growth factor and interleukin-6. Science. 264:95-98. PMID: 8140422

22. Zhou Z, Gushiken FC, Bolgiano D, Salsbery BJ, Aghakasiri N, Jing N, et al. 2013. Signal transducer and activator of transcription 3 (STAT3) regulates collagen-induced platelet aggregation independently of its transcription factor activity. Circulation. 127:476-485. doi: 10.1161/CIRCULATIONAHA.112. 132126 PMID: 23266857

23. Hu H, Forslund M, Li N. 2005. Influence of extracellular calcium on single platelet activation as measured by whole blood flow cytometry. Thromb. Res. 116:241-247. PMID: 15935833

24. Zhang Y, Liu X, Liu L, Zaske AM, Zhou Z, Fu Y, et al. 2013. Contact- and agonist-regulated microvesiculation of human platelets. Thromb. Haemost. 110:331-339. doi: 10.1160/TH12-11-0853 PMID: 23784603

25. Bosin TR, Schaltenbrand SL. 1991. Stimulation of platelet serotonin transport by substituted 1,4naphthoquinone-induced oxidant stress. Biochem. Pharmacol. 41:967-974. PMID: 1848980

26. Milsom JP, Morgan MY, Sherlock S. 1979. Factors affecting plasma amino acid concentrations in control subjects. Metabolism. 28:313-319. PMID: 571951

27. Essex DW, and Li M. 2003. Redox control of platelet aggregation. Biochemistry. 42:129-136. PMID: 12515547 
28. Wegenka UM, Buschmann J, Lutticken C, Heinrich PC, Horn F. 1993. Acute-phase response factor, a nuclear factor binding to acute-phase response elements, is rapidly activated by interleukin- 6 at the posttranslational level. Mol. Cell Biol 13:276-288. PMID: 7678052

29. Lutticken C, Wegenka UM, Yuan J, Buschmann J, Schindler C, Ziemiecki A, et al. 1994. Association of transcription factor APRF and protein kinase Jak1 with the interleukin-6 signal transducer gp130. Science 263:89-92. PMID: 8272872

30. Wen Z, Zhong Z, Darnell JE Jr. 1995. Maximal activation of transcription by Stat1 and Stat3 requires both tyrosine and serine phosphorylation. Cell. 82:241-250. PMID: 7543024

31. Reich NC, Liu L. 2006. Tracking STAT nuclear traffic. Nat. Rev. Immunol. 6:602-612. PMID: 16868551

32. Gkaliagkousi E, Ritter J, Ferro A. 2007. Platelet-derived nitric oxide signaling and regulation. Circ. Res. 101:654-662. PMID: 17901370 